\title{
e-interview
}

columns

\section{Pat Bracken}

Pat Bracken is a Consultant Psychiatrist and Clinical Director of Mental Health Services in West Cork, Ireland. He is also Professor of Philosophy, Diversity and Mental Health at the University of Central Lancashire in the UK. He trained in psychiatry and philosophy in Cork and in Birmingham. His interests include collaborating with user/survivors, developing critical thinking in psychiatry and working with asylum seekers and refugees.

If you were not a psychiatrist, what would you do?

I would have loved to have been an artist but I didn't have the talent. A full-time career in philosophy would be my other choice.

\section{Do you feel stigmatised by your} profession?

Not stigmatised as such. I do pick up a sense of frustration from medical colleagues in relation to psychiatry. Some of this could be avoided if psychiatry was a bit more honest about what it could and couldn't do.

What are your interests outside of work?

My family, astronomy, messing about with the local drama group.

Who was your most influential trainer, and why?

I have been fortunate to work with some great trainers in Ireland and the UK. I think David Dunne in Cork showed me that, in the end, good mental health work had more to do with caring relationships than anything else.

What job gave you the most useful training experience?

Working in Uganda for the Medical Foundation for the Care of Victims of Torture in the late 1980s. This challenged many of the ideas I had accumulated during my early training, particularly about the nature of therapy and healing. I also learned about the crucial role played by social and cultural contexts both in shaping our emotional reactions and our attempts to understand them.

\section{Which publication has influenced} you most?

Hubert Dreyfus' Being-in-the-World. This is a commentary on Heidegger's Being and

Time. The latter is notoriously difficult, but together these works are a powerful antidote to the Cartesian assumptions that



underscore a great deal of psychiatric theory. Heidegger wants us to think beyond the idea that we exist as individual minds relating to an outside world. I think we are just beginning to understand the full implications of this for our work.

What is the most promising opportunity facing the profession? The rise of the user/survivor movement. This has opened up fantastic possibilities for dialogue, possibilities that were simply not available when I started training 25 years ago.

What is the greatest threat?

Further corruption of the academic environment by the interests of the pharmaceutical industry.

\section{What single change would} substantially improve quality of care? Work to promote a 'community development' approach to mental health. So far, community psychiatry has been limited to clinics or teams operating in the community. Alongside user/survivor and carer organisations, we need to engage the whole community in a democratic debate about mental health. Most of the disasters in our history have been due to the social exclusion of people who experience states of madness. A'community development' approach holds out the possibility of overcoming this.

What is the most important advice you could offer to a new trainee? To keep an open mind and a questioning spirit. I usually encourage my trainees to actively explore the critical literature on psychiatry as well as studying for their exams.

Do you think psychiatry is brainless or mindless?

Neither. In fact, I think it has been too focused on both. What it has lacked is an orientation towards contextual factors.
How we understand both the brain and the mind is shaped to a large extent by background assumptions, frameworks and priorities. Philosophy, anthropology, history and critical thought have tools that can help us to understand these. Psychiatry needs to prioritise its involvement with these disciplines.

What is the role of the psychiatrist in rebuilding healthcare systems? If psychiatry can escape from its current bioreductionist orientation it has a lot to offer. We need to see that what makes psychiatry special is its primary focus on the meaningful aspects of human reality: beliefs, behaviours, emotion, relationships etc. Other doctors (like neurologists for example) deal with these, but they are generally of secondary importance to their concern with what is happening in terms of anatomy and physiology. Our challenge is to develop a form of medicine that is adequate to human meaning. If we can do that, psychiatry could genuinely offer leadership in healthcare.

What single area of psychiatric research should be given priority? I believe that we need to find ways of getting beyond the evidence-based practice paradigm. This seeks to determine what technical parts of our interventions are successful. It seeks to exclude what are called 'non-specific' aspects of care. In doing this, it underscores the predominance of the technical and systematically relegates these non-specific issues to the sidelines. But these issues have to do with personal relationships, contexts, values and meanings, and these are the very things that users/survivors are telling us are important. We know from years of psychotherapy research that it is the nonspecific aspects of therapy that determine outcomes and recent meta-analyses of antidepressant trials have served to underscore the importance of the placebo effect in psychopharmacology. Our job in the next 20 years is to find ways to work collaboratively with users/survivors, carers and the wider community to research and explore these aspects of care as our central concern.

Dominic Fannon

doi: 10.1192/pb.bp.108.021105 